Check for updates

Cite this: New J. Chem., 2017, 41, 11258

Received 26th June 2017, Accepted 28th August 2017

DOI: 10.1039/c7nj02281f

rsc.li/njc

\title{
Tetranuclear $\mathrm{Ni}(\mathrm{II})$ and Co(II) Schiff-base complexes with an $\mathrm{M}_{4} \mathrm{O}_{6}$ defective dicubane-like core: zero-field SMM behavior in the cobalt analogue $\uparrow$
}

\author{
Ivan Nemec, (D) Radovan Herchel, (D) Marek Machata and Zdeněk Trávníček (D)*
}

\begin{abstract}
Two isostructural tetranuclear $M(\|)_{4}$ complexes with the general formula $\left[M_{4}(\mathrm{~L})_{4}\left(\mathrm{CH}_{3} \mathrm{OH}\right)_{2}\right]$ were prepared by the reaction of $\mathrm{M}\left(\mathrm{CH}_{3} \mathrm{COO}\right)_{2} \cdot 4 \mathrm{H}_{2} \mathrm{O}$ and $\mathrm{H}_{2} \mathrm{~L}$ in the presence of $\operatorname{Pr}_{3} \mathrm{~N}(\mathrm{M}=\mathrm{Ni}$ in 1 , Co in 2 , $\mathrm{H}_{2} \mathrm{~L}=2-\left\{(E)-\left[\left(2-\right.\right.\right.$ hydroxyphenyl)imino]methyl\}phenol, $\operatorname{Pr}_{3} \mathrm{~N}=$ tripropylamine). The crystal structure of 1 was determined by single-crystal $\mathrm{X}$-ray diffraction and it was revealed that it possesses the defective dicubane $\left\{\mathrm{Ni}_{4} \mathrm{O}_{6}\right\}^{2-}$ core with two penta- and two hexacoordinate $\mathrm{Ni}$ atoms. The isostructurality of both complexes was confirmed by powder X-ray diffraction measurements. The analysis of the static magnetic data revealed that the prevailing antiferromagnetic interaction leads to the diamagnetic ground state in $\mathbf{1}$, whereas the ferromagnetic interactions dominate in $\mathbf{2}$. The analysis of magnetic data was supported by broken-symmetry DFT and CASSCF/NEVPT2 calculations, where the latter disclosed large magnetic anisotropy in both compounds. Moreover, the measurements of ac susceptibility in the zero-applied magnetic field confirmed the presence of slow-relaxation of magnetization in $\mathbf{2}$ and thus, this compound behaves as a single-molecule magnet.
\end{abstract}

\section{Introduction}

Single molecule magnets (SMMs) are molecular compounds, which are formed due to the existence of an intrinsic energy barrier $(U)$ capable of preserving their magnetic moment even after the external magnetic field is removed. Since their discovery, ${ }^{1}$ there has been an increasing interest in the preparation of new SMMs with a large $U,^{2}$ as well as in the understanding and explanation of such behavior. ${ }^{3}$ It is well established that the height of $U$ is defined by the relationship $U=|D| \times S^{2}$ for integer spins $(S)$ and $U=|D| \times\left(S^{2}-1 / 4\right)$ for non-integer spins, $D$ being the axial parameter of magnetic anisotropy. In this class of magnetic materials, synthesis of polynuclear transition metal complexes is a very commonly used approach. ${ }^{4}$

Nickel(II) and cobalt(II) coordination compounds are interesting candidates for SMM preparation, because in certain coordination numbers and coordination polyhedron symmetries they can possess very large magnetic anisotropies with large values of the $D$ parameter and these can possibly lead to high

Department of Inorganic Chemistry, Regional Centre of Advanced Technologies and Materials, Faculty of Science, Palacký University, 17. listopadu 12, CZ-77146 Olomouc, Czech Republic.E-mail: zdenek.travnicek@upol.cz $\dagger$ Electronic supplementary information (ESI) available. CCDC 1443521. For ESI and crystallographic data in CIF or other electronic format see DOI: 10.1039/ c7nj02281f values of $U .^{5}$ In particular, the group of polynuclear nickel(II) and cobalt(II) cubane-based compounds have emerged as very interesting candidates for observation of the SMM phenomenon and a large number of such compounds have been reported previously. ${ }^{6}$ The central atoms in such compounds are typically bridged by the phenolato (when ligands are Schiff bases) or alkanoamine oxygen atoms and the bridging angles are due to the cubane topology being close to $90^{\circ}$. This means that the magnetic orbitals are orthogonal and therefore the magnetic coupling is ferromagnetic thus giving rise to a large spin ground state. ${ }^{6 d, g, 7}$ Among tetranuclear nickel(II) and cobalt(II) compounds, the reports on complexes with defective dicubanelike topology ${ }^{8,9}$ are scarcer than those involving complexes with single-cubane topology. ${ }^{6,7,8 e_{f}, 9 b, g, m 10}$ Furthermore, when one inspects the coordination polyhedra in such compounds, complexes with purely hexacoordinate or with both penta- and hexacoordinate central atoms can be distinguished. There are several examples of such hexacoordinate compounds, ${ }^{8 e, 9}$ but only a few examples of compounds with mixed coordination numbers $^{8}$ and, to the best of our knowledge, no detailed investigations of the magnetic properties have been carried out. Recently, we have reported on two tetranuclear nickel(II) compounds containing a tridentate Schiff base ligand $\mathrm{H}_{2} \mathrm{~L}=$ 2-\{(E)-[(2-hydroxyphenyl)imino]methyl $\}$ phenol with cubane and defective dicubane-like topologies and significantly different magnetic behaviours. ${ }^{11}$ In the cubane-based complex, 
$\left[\mathrm{Ni}_{4}(\mathrm{~L})_{4}\left(\mathrm{CH}_{3} \mathrm{OH}\right)_{3}\left(\mathrm{H}_{2} \mathrm{O}\right)\right] \cdot \mathrm{CH}_{3} \mathrm{OH}$, the competing ferro- and antiferromagnetic interactions led to the zero spin ground state, but the compound with the defective dicubane topology, $\left(\mathrm{Pr}_{3} \mathrm{NH}\right)_{2}\left[\mathrm{Ni}_{4}(\mathrm{~L})_{4}\left(\mathrm{CH}_{3} \mathrm{COO}\right)_{2}\right]$, exhibited ferromagnetic coupling between the central atoms and slow relaxation of magnetization in the presence of an external magnetic field. As a continuation of our ongoing study of compounds with defective dicubane topology with use of the $\mathrm{H}_{2} \mathrm{~L}$-type of tridentate Schiff base ligands, herein we report on the preparation of two isostructural compounds with the general formula $\left[\mathrm{M}_{4}^{\mathrm{II}}(\mathrm{L})_{4}\left(\mathrm{CH}_{3} \mathrm{OH}\right)_{2}\right](\mathrm{M}=\mathrm{Ni}(\mathbf{1})$, $\mathrm{Co}(2))$. The crystal structure was determined by single-crystal X-ray diffraction for $\mathbf{1}$, while the isostructurality of $\mathbf{2}$ was confirmed by a powder X-ray diffraction experiment. The static and dynamic magnetic properties of both compounds were thoroughly studied both experimentally and theoretically. Moreover, slow relaxation of the magnetization in a zero applied dc magnetic field was observed for 2 , which is the first example of a singlemolecule magnet with the $\left\{\mathrm{Co}_{4} \mathrm{O}_{6}\right\}^{2+}$ defective dicubane core and mixed hexa- and pentacoordination of the central atoms.

\section{Results and discussion}

\section{Synthesis}

In our previous work, ${ }^{11}$ we reported on the preparation of two $\mathrm{Ni}_{4}$ compounds involving the $\mathrm{H}_{2} \mathrm{~L}$ ligand: $\left[\mathrm{Ni}_{4}(\mathrm{~L})_{4}\left(\mathrm{CH}_{3} \mathrm{OH}\right)_{3}\left(\mathrm{H}_{2} \mathrm{O}\right)\right]$. $\mathrm{CH}_{3} \mathrm{OH}$, (A in Fig. 1), and $\left(\mathrm{Pr}_{3} \mathrm{NH}\right)_{2}\left[\mathrm{Ni}_{4}(\mathrm{~L})_{4}\left(\mathrm{CH}_{3} \mathrm{COO}\right)_{2}\right]$, (B). In their syntheses, the same reactant ratio was employed $\left(\mathrm{Ni}\left(\mathrm{CH}_{3} \mathrm{COO}\right)_{2}: \mathrm{H}_{2} \mathrm{~L}: \mathrm{Pr}_{3} \mathrm{~N}=1: 1: 2\right)$. We revealed that the reaction solvent(s) significantly influenced the structure of the resultant compound. When pure dichloromethane was used, the defective dicubane $\mathrm{Ni}_{4}$ compound with all the $\mathrm{Ni}(\mathrm{II})$ atoms hexacoordinate (B) was prepared, whereas when a $\mathrm{CH}_{2} \mathrm{Cl}_{2} / \mathrm{CH}_{3} \mathrm{OH}$ solvent mixture was used, the cubane $\mathrm{Ni}_{4}$ compound (A) was isolated (Fig. 1). Herein we report on the use of pure methanol as a reaction

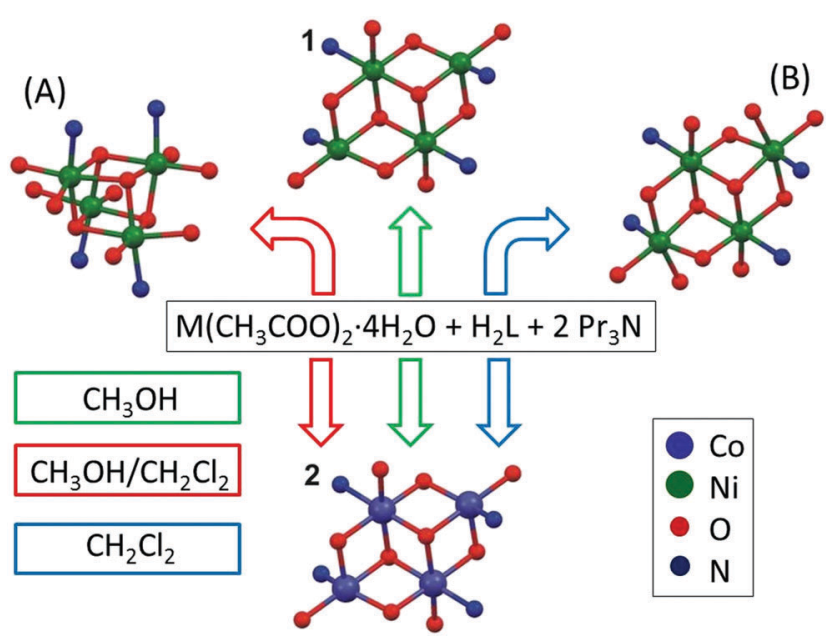

Fig. 1 Scheme of the synthesis of compounds 1, 2 and two other previously published compounds $(A)$ and $(B)$ with the molecular structures of the compounds represented by their $\mathrm{Ni}_{4}$ cores, where $(\mathrm{A})=$ $\left[\mathrm{Ni}_{4}(\mathrm{~L})_{4}\left(\mathrm{CH}_{3} \mathrm{OH}\right)_{3}\left(\mathrm{H}_{2} \mathrm{O}\right)\right] \cdot \mathrm{CH}_{3} \mathrm{OH}$. (B) $=\left(\mathrm{Pr}_{3} \mathrm{NH}\right)_{2}\left[\mathrm{Ni}_{4}(\mathrm{~L})_{4}\left(\mathrm{CH}_{3} \mathrm{COO}\right)_{2}\right]$, $\mathrm{Pr}_{3} \mathrm{NH}^{+}=$the tripropylammonium cation. solvent, which led to the preparation of the third type of the $\mathrm{Ni}_{4}$ compound, we report here as compound $\mathbf{1}$.

Both the herein reported compounds were prepared using a similar synthetic strategy by the reaction of the Schiff base ligand $\mathrm{H}_{2} \mathrm{~L}$, metal(II) acetate salt (nickel - 1 or cobalt - 2) and tripropylamine as the base in the molar ratio of $1: 1: 2$ in methanol. The difference was in their reaction atmospheres and temperature conditions. The preparation of $\mathbf{1}$ was carried out under aerobic conditions and the solution was stirred at its boiling point. The synthesis of 2 was performed under an inert atmosphere $\left(\mathrm{N}_{2}\right)$ at laboratory temperature in order to avoid oxidation of the cobalt(II) atoms. Remarkably, unlike in the case of the nickel(II) complexes, the use of any of the three different reaction media (pure $\mathrm{CH}_{3} \mathrm{OH}, \mathrm{CH}_{2} \mathrm{Cl}_{2} / \mathrm{CH}_{3} \mathrm{OH}$ mixture and pure $\mathrm{CH}_{2} \mathrm{Cl}_{2}$ ) for the preparation of the $\mathrm{Co}(\mathrm{II})$ compound always led to the same product (2) (Fig. 1).

\section{Crystal structures}

The crystal structure of $\mathbf{1}$ was determined by single crystal X-ray structural analysis and the isostructurality of 2 was confirmed by powder X-ray diffraction measurements (see ESI, $\dagger$ Fig. S1). Therefore, only the structure of $\mathbf{1}$ will be discussed. The crystal structure of 1 contains electroneutral complex molecules consisting of four nickel(II) atoms, four doubly deprotonated Schiff base ligands $\mathrm{L}^{2-}$ and two $\mathrm{CH}_{3} \mathrm{OH}$ molecules. The molecular structure of 1 consists of two almost coplanar dinuclear subunits (further abbreviated as $\left\{\mathrm{Ni}_{2}(\mathrm{~L})_{2}\right\}$ ) in a centrosymmetric arrangement with the $\left\{\mathrm{Ni}_{4} \mathrm{O}_{6}\right\}^{2+}$ defective dicubane core (Fig. 2a). The coordination environment of the Ni(II) atoms within $\left\{\mathrm{Ni}_{2}(\mathrm{~L})_{2}\right\}$ differs and the Ni1 atoms are pentacoordinate $\left(\left\{\mathrm{NO}_{4}\right\}\right.$, with the coordination geometry close to squarepyramidal, the value of the Addison parameter ${ }^{12}$ is $\left.\tau=0.39\right) \neq$ and the Ni2 atoms are hexacoordinate $\left(\left\{\mathrm{NO}_{5}\right\}\right.$, Fig. $\left.2 \mathrm{a}\right)$. In the equatorial positions/square base plane, the nickel(II) atoms are coordinated by three donor atoms $\left(\mathrm{NO}_{2}\right.$ donor set) from the ligand $\mathrm{L}^{2-}$ and bridging phenolate oxygen atoms $\left(\mathrm{O}_{\mathrm{Ph}}\right)$ from the adjacent $\mathrm{L}^{2-}$ ligand within $\left\{\mathrm{Ni}_{2}(\mathrm{~L})_{2}\right\}$. The Ni-O bonds $(2.01$ to $2.13 \AA$, besides one exception as explained below) are a bit longer than the Ni-N bonds $(2.009(2)$ and 1.983(4) $\AA$ ). The rather short $\mathrm{Ni}-\mathrm{O}$ distance is provided by the $\mathrm{O}_{\mathrm{Ph}}$ atom, which is the only one not involved in the bridging of the $\mathrm{Ni}$ (II) atoms (O2 in Fig. 2b). The axial position for the pentacoordinate Ni1 central atom is occupied by the $\mu-\mathrm{O}_{\mathrm{Ph}}(\mathrm{Ni1}, d(\mathrm{Ni}-\mathrm{O})=2.0369(18) \AA)$ atoms from the symmetrically related $\left\{\mathrm{Ni}_{2}(\mathrm{~L})_{2}\right\}$ subunit. Also, one axial position of the Ni2 center is occupied by the bridging $\mu^{3}-\mathrm{O}_{\mathrm{Ph}}$ $(d(\mathrm{Ni}-\mathrm{O})=2.1332(18) \AA)$ atom. The second position is occupied by the oxygen atom of the coordinated $\mathrm{CH}_{3} \mathrm{OH}$ molecule $(d(\mathrm{Ni}-\mathrm{O})=$ $2.079(3) \AA)$. The $\mathrm{Ni} \cdots \mathrm{Ni}$ separation within $\left\{\mathrm{Ni}_{2}(\mathrm{~L})_{2}\right\}$ is 3.1028(6) $\mathrm{A}$, while the closest $\mathrm{Ni} \cdot \cdots \mathrm{Ni}$ separation between the subunits is a bit shorter (3.0918(5) $\mathrm{A})$. The Ni-O-Ni angles within $\left\{\mathrm{Ni}_{2}(\mathrm{~L})_{2}\right\}$ are in the range of $98.34(7)-100.07(8)^{\circ}$. The $\mathrm{Ni}-\mathrm{O}-\mathrm{Ni}$ angles between the symmetry related nickel(II) atoms adopt a larger range of values: 94.51(7), 98.80(8) and 100.34(7) ${ }^{\circ}$.

$\ddagger \tau=0$ for ideal square pyramidal and $\mathbf{1}$ for ideal trigonal bipyramidal geometry. 


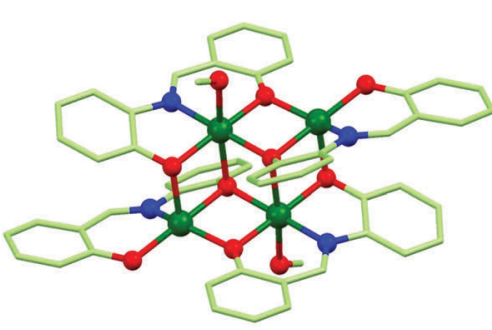

(a)

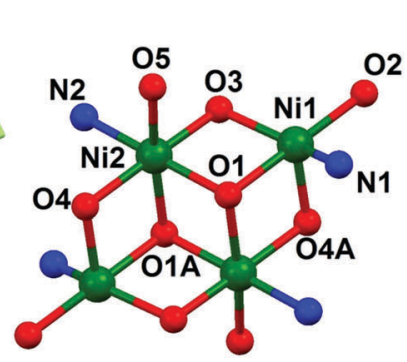

(b)

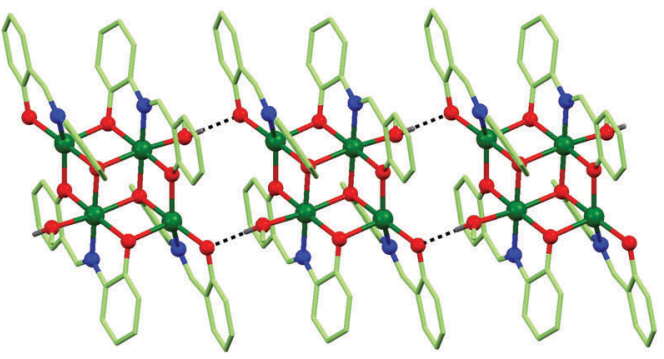

(c)

Fig. 2 Molecular (a) and crystal (c) structures of 1 with the depicted defective dicubane core (b). Bond distances (in $\AA$ ) within the coordination polyhedron of 1: $(\mathrm{Ni1}-\mathrm{O} 1)=2.0763(17),(\mathrm{Ni1}-\mathrm{O} 2)=1.9772(17),(\mathrm{Ni1}-\mathrm{O} 3)=2.0384(18),(\mathrm{Ni1}-\mathrm{O} 4 \mathrm{~A})=2.0369(18),(\mathrm{Ni1}-\mathrm{N} 1)=2.009(2),(\mathrm{Ni2}-\mathrm{O} 1)=$ 2.0239(17), $(\mathrm{Ni2}-\mathrm{O} 1 \mathrm{~A})=2.1332(18),(\mathrm{Ni2}-\mathrm{O} 3)=2.0100(17),(\mathrm{Ni2}-\mathrm{O} 4)=2.0350(17),(\mathrm{Ni2}-\mathrm{O} 5)=2.0776(19),(\mathrm{Ni2}-\mathrm{N} 2)=1.983(4)$.

The coordinated $\mathrm{CH}_{3} \mathrm{OH}$ molecules form $\mathrm{O}-\mathrm{H} \cdots \mathrm{O}$ hydrogen bonds between the oxygen atom from $\mathrm{CH}_{3} \mathrm{OH}$ and the $\mathrm{O}_{\mathrm{Ph}}$ atom from the complex anion (Fig. 2b) with $d(\mathrm{O} \cdots \mathrm{O})=2.754(4) \AA$. Thus, the complex molecules are arranged into 1D supramolecular chains (Fig. 2c).

\section{Magnetic properties}

Description of magnetic properties. The temperature and field dependent magnetic data of $\mathbf{1}$ and $\mathbf{2}$ are depicted in Fig. 3.

The room temperature experimental values, $6.6 \mu_{\mathrm{B}}$ and $9.8 \mu_{\mathrm{B}}$, for 1 and 2 , respectively, are higher than the theoretical values for the four non-interacting Ni(II) (1) or $\mathrm{Co}$ (II) (2) atoms with $S_{\mathrm{i}}=1$ (1) or $3 / 2$ (2) equal to $5.7 \mu_{\mathrm{B}}$ or 8.7 for $g=2.0$ due to the contribution of the orbital angular momentum to the ground spin state $(g>2.0)$. Temperature dependent data for 1 are almost constant down to $100 \mathrm{~K}$, but then $\mu_{\text {eff }}$ starts to decrease on further cooling reaching the value of $1.3 \mu_{\mathrm{B}}$ at $1.9 \mathrm{~K}$. The temperature data for 2 show gradual increase of $\mu_{\text {eff }} / \mu_{\mathrm{B}}$ on lowering the temperature up to the maximal value of 14.3 found at $8.1 \mathrm{~K}$, further cooling leads to a decrease to the value of 10.8 at $1.9 \mathrm{~K}$. The character of the variable temperature data for 1 indicates the prevailing antiferromagnetic intracluster coupling, but in the case of $\mathbf{2}$ ferromagnetic intracluster coupling dominates.

Before the analysis of the experimental magnetic data of 1 and 2 , the predictive role of $a b$ initio calculations in magnetochemistry was utilized with the aim of estimating the principal parameters describing the exchange coupling and the zero-field splitting in these molecular systems. ${ }^{13-15}$ Therefore, Density Functional Theory (DFT) was applied to calculate the parameters of the isotropic exchange $J_{a b}$ between the paramagnetic ions, and the multireference method based on Complete Active Space Self Consistent Field (CASSCF) was utilized to derive information about the single-ion zero-field splitting tensor parameters $D$ and $E$. Having such information at our disposal, the trustworthy spin Hamiltonians can be postulated and the calculated parameters can be used as a starting point for fitting of the experimental magnetic data. All theoretical calculations were performed with a freely available computational package ORCA. ${ }^{16}$ All the calculations were done for molecular geometries extracted from X-ray data and also for molecular geometries
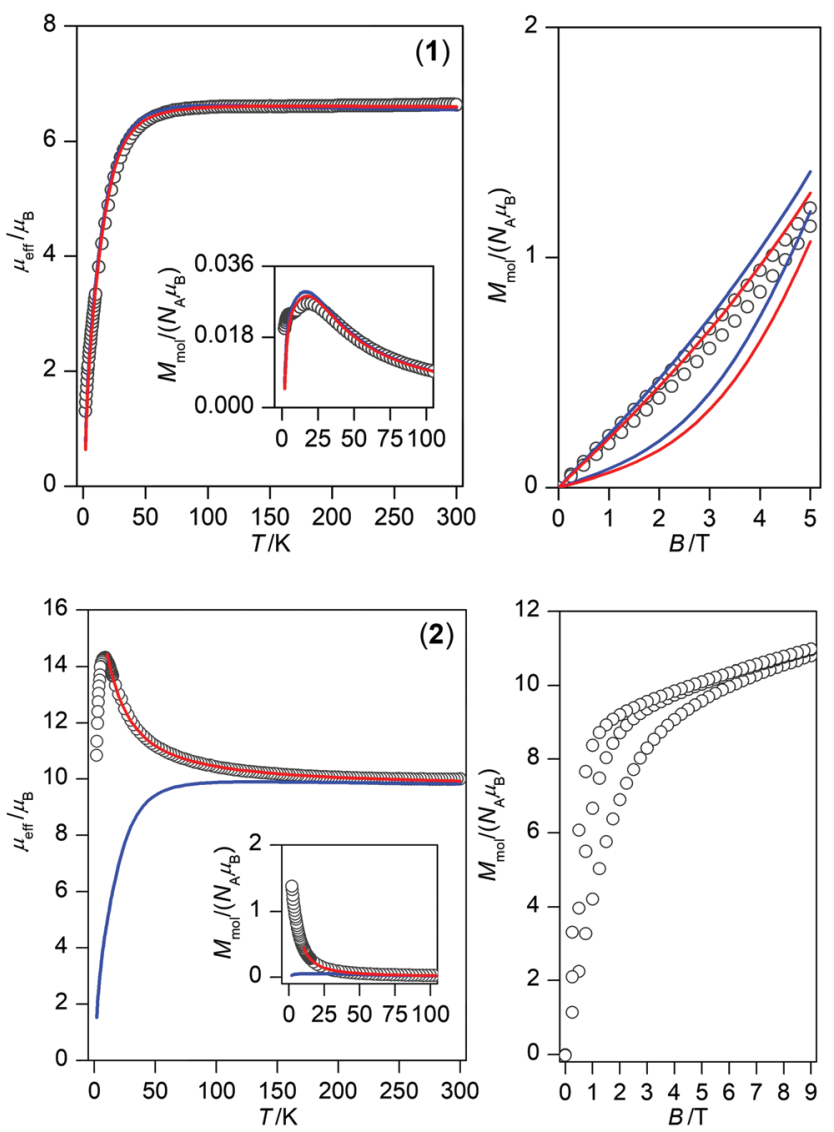

Fig. 3 Temperature and field dependent magnetic data for compounds 1 (top) and 2 (bottom). Experimental data - circles. Calculated data for 1: BS-DFT: $J_{1}=-10.6 \mathrm{~cm}^{-1}, J_{2}=+20.7 \mathrm{~cm}^{-1}, J_{3}=+2.51 \mathrm{~cm}^{-1}, g=2.28$ (blue line); analysis of experimental data (eqn (3)): $J_{1}=-10.1 \mathrm{~cm}^{-1}$, $J_{2}=+15.5 \mathrm{~cm}^{-1}, J_{3}=0, g=2.32$ (red line). Calculated data for 2 : BS-DFT: $J_{1}=-6.65 \mathrm{~cm}^{-1}, J_{2}=+13.0 \mathrm{~cm}^{-1}, J_{3}=+0.127 \mathrm{~cm}^{-1}, g=2.49$ (blue line); analysis of experimental data (eqn (3)): $J_{1}=+1.84 \mathrm{~cm}^{-1}$, $J_{2}=+7.35 \mathrm{~cm}^{-1}, J_{3}=0, g=2.49$ (red line).

optimized with the BP86 functional (see the Experimental section for more details).

DFT calculations of the isotropic exchange. The calculations of $J_{a b}$ are based on comparing the energy differences between the high spin (HS) and broken-symmetry (BS) spin states. ${ }^{17}$ 
These energies for tetranuclear molecular fragments were calculated with the B3LYP hybrid functional incorporating also the relativistic effects with the 0th order regular approximation (ZORA) using a relativistic version of the polarized triple- $\xi$ quality basis set def2-TZVP(-f) for all atoms. In the case of compound 2 , the molecular geometry was constructed from 1 by replacing nickel atoms by cobalt atoms. There are two symmetrically independent metal atoms within the tetramers (Fig. 2) and three different superexchange pathways, which can be described by this spin Hamiltonian

$$
\hat{H}=-J_{1}\left(\vec{S}_{1} \cdot \vec{S}_{2}+\vec{S}_{1^{\prime}} \cdot \vec{S}_{2^{\prime}}\right)-J_{2}\left(\vec{S}_{1} \cdot \vec{S}_{2^{\prime}}+\vec{S}_{1^{\prime}} \cdot \vec{S}_{2}\right)-J_{3}\left(\vec{S}_{2} \cdot \vec{S}_{2^{\prime}}\right)
$$

where $J_{1}$ corresponds to the $\mathbf{M} 1-\mathbf{M} 2$ and $\mathbf{M} 1^{\mathrm{i}}-\mathbf{M} 2^{\mathrm{i}}$ pairs with the interatomic distance equal to $3.103 \AA$, $J_{2}$ corresponds to the $\mathrm{M} 1-\mathrm{M} 2{ }^{\mathrm{i}}$ and $\mathrm{M} 1-\mathrm{M} 2^{\mathrm{i}}$ pairs with the interatomic distance equal to $3.092 \AA$ and $J_{3}$ corresponds to the $\mathrm{M} 2-\mathrm{M} 22^{\mathrm{i}}$ pair with the interatomic distance equal to $3.193 \AA$ (Fig. 4). Several BS spin states were calculated, namely BS11', BS12 and BS12', and their energy differences with the HS spin state, $\Delta_{a b}=\varepsilon_{\mathrm{BS} a b}-\varepsilon_{\mathrm{HS}}$, were employed in the calculations of the $J$-parameters by applying Ruiz's approach as

$$
\begin{aligned}
& J_{1}=\left(+\Delta_{11^{\prime}}-\Delta_{12}+\Delta_{12^{\prime}}\right) / 12 \\
& J_{2}=\left(+\Delta_{11^{\prime}}+\Delta_{12}-\Delta_{12^{\prime}}\right) / 12 \\
& J_{3}=\left(-\Delta_{11^{\prime}}+\Delta_{12}+\Delta_{12^{\prime}}\right) / 6 \\
& J_{1}=\left(+\Delta_{11^{\prime}}-\Delta_{12}+\Delta_{12^{\prime}}\right) / 24 \\
& J_{2}=\left(+\Delta_{11^{\prime}}+\Delta_{12}-\Delta_{12^{\prime}}\right) / 24 \\
& J_{3}=\left(-\Delta_{11^{\prime}}+\Delta_{12}+\Delta_{12^{\prime}}\right) / 12
\end{aligned}
$$

where eqn (2a) holds for nickel complex 1 and eqn (2b) holds for cobalt complex 2 . The calculation details are listed in Tables 1 and 2 and the spin densities of the HS spin states are shown in Fig. S2 and S3 (ESI $\dagger$ ) for 1 and 2, respectively. The partial spin delocalization from the metal atoms to the respective donor atoms is clearly visible. Next, the $J$-parameters calculated according to eqn (2) adopted the values $J_{1}=-10.6 \mathrm{~cm}^{-1}$, $J_{2}=+20.7 \mathrm{~cm}^{-1}$ and $J_{3}=+2.51 \mathrm{~cm}^{-1}$ for 1 and $J_{1}=-6.65 \mathrm{~cm}^{-1}$, $J_{2}=+13.0 \mathrm{~cm}^{-1}$ and $J_{3}=+0.127 \mathrm{~cm}^{-1}$ for 2 for geometries extracted

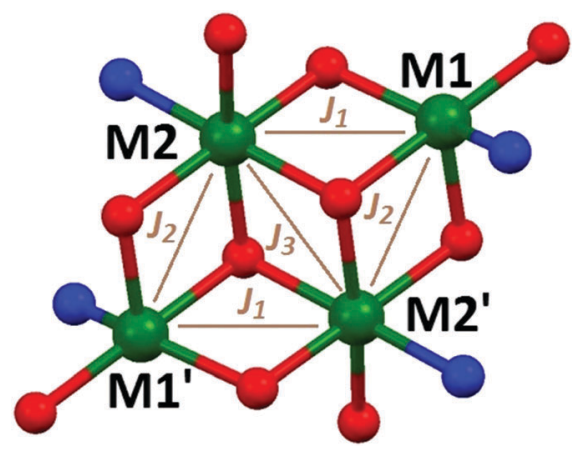

Fig. 4 Scheme of the magnetic exchange pathways in $\mathbf{1}(\mathrm{M}=\mathrm{Ni})$ and $2(\mathrm{M}=\mathrm{CO})$. from experimental X-ray data. Analogous calculations for optimized geometries resulted in similar values of the parameters: $J_{1}=-7.73 \mathrm{~cm}^{-1}, J_{2}=+20.6 \mathrm{~cm}^{-1}$ and $J_{3}=+3.33 \mathrm{~cm}^{-1}$ for 1 and $J_{1}=-6.56 \mathrm{~cm}^{-1}, J_{2}=+12.4 \mathrm{~cm}^{-1}$ and $J_{3}=+0.175 \mathrm{~cm}^{-1}$ for 2 . Evidently, there are competing antiferromagnetic and ferromagnetic interactions in $\mathbf{1}$ and 2, but there is no simple correlation of the calculated $J$-parameters with either the $\mathbf{M}-\mathrm{O}-\mathbf{M}$ angle (Fig. S4, ESI $\dagger$ ), or the M $\cdots$ M distance (Fig. S5, ESI $\dagger$ ).

Multi-reference calculations of the single-ion zero-field splitting tensors. The single-ion zero-field splitting parameters and $g$-factors in compounds 1 and $\mathbf{2}$ were calculated using multireference state average complete active space (SA-CASSCF) wavefunctions complemented by N-electron valence state perturbation theory (NEVPT2) with $\operatorname{CAS}(8,5)$ and $\operatorname{CAS}(7,5)$ active spaces, respectively. Again, the same basis set was used and also relativistic effects were included with ZORA. This method is generally used to extract information about magnetic anisotropy for transition metal complexes. Herein, we used the molecular geometry of the whole tetranuclear complex and by replacing three of the four metal atoms with diamagnetic zinc atoms, the single-ion ZFS tensors were calculated for individual crystalographically independent $\mathrm{Ni}$ or Co atoms.

The results for $\mathbf{1}$ are summarized in Table 3. The energy levels and the contributions of the excited spin states to the $D$-tensor are listed in Tables S2 and S3 (ESI $\dagger$ ). The individual $D$-tensor axes are visualized in Fig. S6 and S7 (ESI $\dagger$ ) for 1, and 2, respectively. The values of the zero-field splitting parameters and $g$ factors vary over a wider range due to the different coordination numbers of the central atoms (Table 3 ). The calculated $D=+26.8 \mathrm{~cm}^{-1}$ for the Ni1 atom with $\tau=0.39$ is not in accordance with the recently published magneto-structural correlation of the pentacoordinate $\mathrm{Ni}$ (II) complexes, ${ }^{18}$ where $D=32.7-151 \cdot \tau=-26.2 \mathrm{~cm}^{-1}$ would be expected. The discrepancy in the sign of $D$ could be explained by the different chromophore of $\mathrm{Ni1},\left\{\mathrm{NiO}_{4} \mathrm{~N}\right\}$, as compared to the data in ref. 18, where all the compounds possessed the $\left\{\mathrm{NiO}_{2} \mathrm{~N}_{3}\right\}$ chromophore. $D=-9.47 \mathrm{~cm}^{-1}$ computed for $\mathrm{Ni} 2$ is in the range of hexacoordinate $\mathrm{Ni}(\mathrm{II})$ complexes. ${ }^{19}$ Moreover, both $\mathrm{Ni}$ (II) atoms possess a large rhombicity $(E / D>0.25)$, which practically means that the sign of $D$ becomes irrelevant. The ZFS of pentacoordinate Co(II) complexes was recently studied ${ }^{20}$ and it was shown that for $\tau>0.29$, positive $D$ is expected. Thus, $D=+48.2 \mathrm{~cm}^{-1}$ for Co1 seems to be in accordance with this prediction. For hexacoordinate $\mathrm{Co} 2$, an even larger $D=+76.0 \mathrm{~cm}^{-1}$ was found, which is in the range of similar Co(II) compounds. $^{21}$ Moreover, both $\mathrm{Co}(\mathrm{II})$ atoms possess a large rhombicity $(E / D>0.19)$, which practically means that the sign of $D$ is irrelevant. Thus, the axial type of the magnetic anisotropy should be observed for these ions. ${ }^{5 c, 20}$ However, the CASSCF/NEVPT2 calculations for both Co1 and Co2 atoms also showed that there were close lying excited states with energies equal to 1022 and $678 \mathrm{~cm}^{-1}$ (Table S2, ESI $\dagger$ ), respectively. Therefore, the spin Hamiltonian formalism is not valid anymore, and the extracted values of the ZFS parameters and $g$-tensors must be treated with great care. This is also evident from the calculated value $g_{z}=1.939$ for $\mathrm{Co} 2$ (Table 3), which contradicts the expected $g_{i}>2.0$ for the $3 \mathrm{~d}^{7}$ electronic configuration. 
Table 1 The B3LYP/ZORA/def2-TZVP(-f) calculated net Mulliken spin densities, the $\left\langle S^{2}\right\rangle$ values and relative energies of the high-spin (HS) and broken-symmetry spin (BS) states for the molecular fragment $\left[\mathrm{Ni}_{4}\left(\mathrm{~L}_{4}\left(\mathrm{CH}_{3} \mathrm{OH}\right)_{2}\right]\right.$ of $\mathbf{1}^{a}$

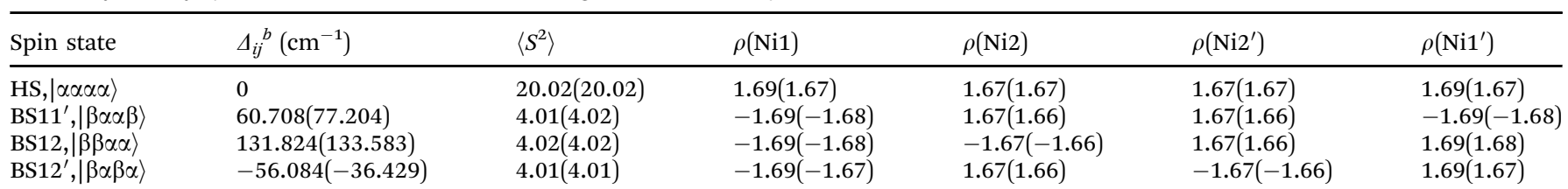

${ }^{a}$ The values in parentheses were calculated for optimized geometries (see Experimental section for more details). ${ }^{b} \Delta_{i j}=\varepsilon_{\mathrm{BS} i j}-\varepsilon_{\mathrm{HS}}$.

Table 2 The B3LYP/ZORA/def2-TZVP(-f) calculated net Mulliken spin densities, the $\left\langle S^{2}\right\rangle$ values and relative energies of the high-spin (HS) and broken-symmetry spin (BS) states for the molecular fragment $\left[\mathrm{CO}_{4}(\mathrm{~L})_{4}\left(\mathrm{CH}_{3} \mathrm{OH}\right)_{2}\right]$ of $\mathbf{2}^{a}$

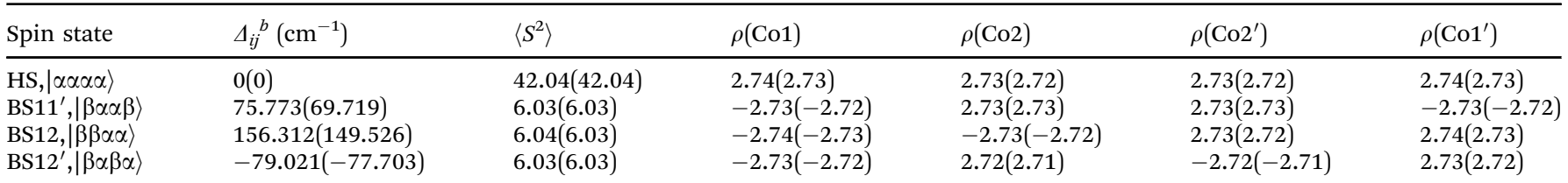

${ }^{a}$ The values in parentheses were calculated for optimized geometries (see Experimental section for more details). ${ }^{b} \Delta_{i j}=\varepsilon_{\mathrm{BS} i j}-\varepsilon_{\mathrm{HS}}$.

Table 3 The CASSCF/NEVPT2/ZORA/def2-TZVP(-f) calculated ZFS parameters and $g$-factors for the Ni(॥) and Co(II) atoms in compounds $\mathbf{1}$ and $\mathbf{2}^{a}$

\begin{tabular}{|c|c|c|c|c|c|c|}
\hline & Atom & $D\left(\mathrm{~cm}^{-1}\right)$ & $E / D$ & $g_{x}$ & $g_{y}$ & $g_{z}$ \\
\hline & $\mathrm{Ni} 2$ & $-9.47(+9.37)$ & $0.294(0.246)$ & $2.213(2.219)$ & $2.167(2.163)$ & $2.259(2.254)$ \\
\hline
\end{tabular}

${ }^{a}$ The values in italics must be taken with great care, because the first excited state is relatively close to the ground state.

Actually, it seems that the ${ }^{4} \mathrm{~F}$ atomic term of $\mathrm{Co}(\mathrm{II})$ is split into a set of close-lying Kramers doublets (Table S2, ESI $\dagger$ ), which resembles the situation generally found for other lanthanidebased Kramers ions, such as Dy(III) or Er(III). To evaluate the magnetic anisotropy in such systems, the individual Kramers doublets are usually treated with the effective spin Hamiltonian for $S_{\text {eff }}=1 / 2$, which results in $g_{\text {eff }}$-tensors. Then, the $g$-anisotropy is a measure of the magnetic anisotropy. Such a procedure applied for the ground Kramers doublets of Co1 and Co2 revealed $g_{\text {eff }, x}=1.622, g_{\text {eff } y}=2.626, g_{\text {eff }, z}=7.422$ and $g_{\text {eff }, x}=2.097, g_{\text {eff }, y}=$ $3.349, g_{\text {eff }, z}=6.751$, respectively. Obviously, there is the axial type of the magnetic anisotropy $\left(g_{\text {eff }, z} \gg g_{\text {eff }, x, y}\right)$, but with a significant rhombic character $\left(g_{\text {eff } x, y}>0\right)$. In the case of the BP86-optimized geometries of 1 and 2, the hexacoordinate M2 and M2' metal atoms are little affected by a small change of the coordination geometry, and the CASSCF/NEVPT2 calculated ZFS parameters, $|D|$ and $E / D$, are very similar to those calculated for the geometries extracted from X-ray data, see Table 3 and Tables S6, S7 $(\mathrm{ESI} \dagger)$. The same also holds for the pentacoordinate Ni1 $\left(\mathrm{Ni}^{\prime}\right)$ atoms where upon geometry optimization the $\tau$ shifted from 0.39 to the value of 0.41 , hence the ZFS parameters are almost the same, e.g. $D$ changed from $+26.8 \mathrm{~cm}^{-1}$ to $+27.7 \mathrm{~cm}^{-1}$, see Table 3 . In contrast, the coordination geometry of pentacoordinate Co1 $\left(\mathrm{Co1}^{\prime}\right)$ atoms considerably changed as manifested by the increase of $\tau$ from 0.39 to 0.57 . This significant distortion can be attributed to the Jahn-Teller effect, which operates for squarepyramid geometry due to the ${ }^{4} E$ ground state. Such a large change of $\tau$ is reflected also in the ZFS parameters, $D$ changed from $+48.2 \mathrm{~cm}^{-1}$ to $-22.4 \mathrm{~cm}^{-1}$, but leaving the rhombicity still very large, $E / D=0.30$. Analogous analysis of the ground Kramers doublets with the effective spin $S_{\text {eff }}=1 / 2$ for Co1 and Co2 centers resulted in $g_{\text {eff }, x}=1.478, g_{\text {eff }, y}=2.112, g_{\text {eff }, z}=$ 6.920 and $g_{\text {eff }, x}=2.170, g_{\text {eff }, y}=2.916, g_{\text {eff }, z}=7.058$, respectively. Thus, the results obtained for the optimized geometry of 2 also show the axial type of the magnetic anisotropy $\left(g_{\text {eff }, z} \gg g_{\text {eff }, x, y}\right)$ with a substantial rhombic character $\left(g_{\text {eff }, x, y}>0\right)$.

Analysis of the experimental magnetic data. Based on the molecular structures of $\mathbf{1}$ and $\mathbf{2}$, the following spin Hamiltonian can be postulated

$$
\begin{aligned}
\hat{H}= & -J_{1}\left(\vec{S}_{1} \cdot \vec{S}_{2}+\vec{S}_{1^{\prime}} \cdot \vec{S}_{2^{\prime}}\right)-J_{2}\left(\vec{S}_{1} \cdot \vec{S}_{2^{\prime}}+\vec{S}_{1^{\prime}} \cdot \vec{S}_{2}\right)-J_{3}\left(\vec{S}_{2} \cdot \vec{S}_{2^{\prime}}\right) \\
& +\sum_{i=1}^{4} D_{i}{ }^{\prime}\left(\hat{S}_{z}^{2}-\hat{S}^{2} / 3\right)+E_{i}^{\prime}\left(\hat{S}_{x}^{2}-\hat{S}_{y}{ }^{2}\right)+\mu_{\mathrm{B}} B_{a} \sum_{i=1}^{4} g \hat{S}_{a}
\end{aligned}
$$

where the isotropic exchange, the zero-field splitting and Zeeman terms were included. Evidently, there are too many free parameters $\left(J_{1}, J_{2}, J_{3}, D_{1}, E_{1}, D_{2}, E_{2}, g\right)$ to fit the experimental magnetic data. To avoid over-parameterization, firstly, we focused on the temperature-dependent data of $\mathbf{1}$, where the prevailing antiferromagnetic exchange should lead to the nonmagnetic ground spin state little affected by the zero-field splitting. As a result, there are only four parameters $\left(J_{1}, J_{2}, J_{3}, g\right)$ 

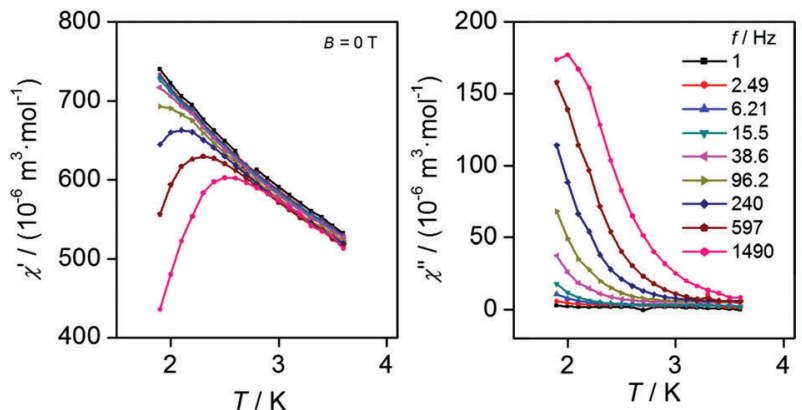

(a)
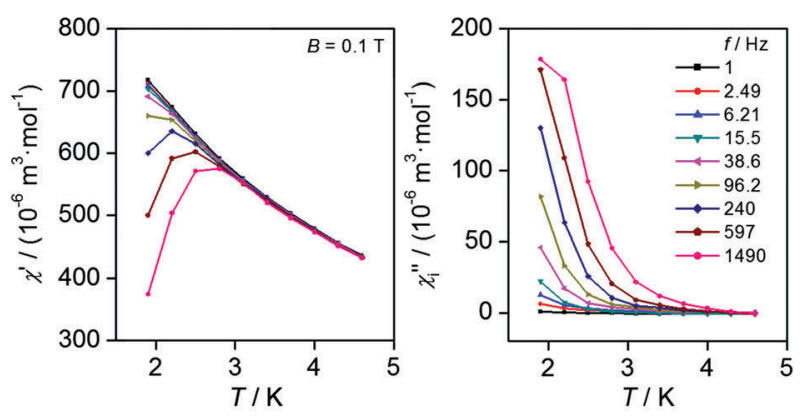

(b)

Fig. 5 AC susceptibility measurements in zero (a) and non-zero $(B=0.1 \mathrm{~T})$ applied magnetic field (b) for 2

to vary. Interestingly, the DFT-calculated $J$-parameters $\left(J_{1}=\right.$ $\left.-10.6 \mathrm{~cm}^{-1}, J_{2}=+20.7 \mathrm{~cm}^{-1}, J_{3}=+2.51 \mathrm{~cm}^{-1}, g=2.28\right)$ describe the magnetic data of 1 very well (Fig. 3). Actually, a good fit was already obtained for the case where we neglected the smallest exchange parameter $\left(J_{3}=0\right)$ and we found $J_{1}=-10.1 \mathrm{~cm}^{-1}, J_{2}=$ $+15.5 \mathrm{~cm}^{-1}, J_{3}=0$ (fixed), and $g=2.32$ (Fig. 3). These parameter's sets describe also the isothermal magnetization data fairly well, especially at $T=5 \mathrm{~K}$ (Fig. 3). Further improvement would be obtained by introducing also ZFS parameters $\left(D_{1}, E_{1}, D_{2}, E_{2}\right)$, however, this would lead to over-parameterization and thus would result in untrustworthy parameters. A similar approach was adopted for 2. At first, the J-parameters calculated from DFT were used to simulate magnetic data (Fig. 3), but there was a surprisingly large discrepancy. This can be explained by the fact that CASSCF/NEVPT2 calculations showed that the spin Hamiltonian is not applicable for the cobalt ions due to low-lying excited states.

We encountered a similar inconsistency between the DFTcalculated $J$-parameters and experimental magnetic data for the dinuclear compound $\left[\mathrm{Co}_{2}(\text { bedmpzp })_{2}(\mu-\mathrm{Cl})_{2}\right]\left(\mathrm{PF}_{6}\right)_{2}$ (bedmpzp $=$ bis(3,5-dimethyl-1 $H$-pyrazol-1-yl-1-ethyl)(2-pyridylmethyl)amine), where CASSCF/NEVPT2 calculations were also performed and indicated the presence of close-lying excited states. ${ }^{22}$ Of course, we tried to fit the magnetic data of $\mathbf{2}$ with the spin Hamiltonian in eqn (3) neglecting the zero-field splitting terms in the temperature range from 10 to $300 \mathrm{~K}$ and good fits were obtained with $J_{1}=+1.41 \mathrm{~cm}^{-1}, J_{2}=+7.30 \mathrm{~cm}^{-1}, J_{3}=+0.84, g=2.49$ or also for $J_{1}=+1.84 \mathrm{~cm}^{-1}, J_{2}=+7.35 \mathrm{~cm}^{-1}, J_{3}=0$ (fixed), $g=2.49$ (Fig. 3). Nevertheless, we must stress here that despite the fact that the magnetic data of 2 can be fitted within the spin Hamiltonian formalism, a more sophisticated model including the contribution of the orbital angular momentum is needed to properly describe the experimental data. Such an approach, known as the Griffith-Figgis formalism, is only available for (pseudo)octahedral $\mathrm{Co}$ (II) complexes ${ }^{23}$ and is completely missing for pentacoordinate $\mathrm{Co}$ (II) compounds. Furthermore, there is an unsolved problem, i.e. how to treat magnetic exchange among $\mathrm{Co}(\mathrm{II})$ atoms in the situation where the spin Hamiltonian is not applicable. Usually, in the case of the Kramers ions, the exchange can be treated with the Ising model, however, this is not permitted in our case, because according to CASSCF/ NEVPT2 calculations, the effective $g$-factors for $S_{\text {eff }}=1 / 2$ are all non-zero. Thus, we must conclude that the analysis of the magnetic data for polynuclear complexes with a large contribution of the angular momentum is still a great challenge for magnetochemistry.

Dynamic magnetic data. The ferromagnetic coupling and significant magnetic anisotropy found in 2 encouraged us to study also the dynamic magnetic properties. Therefore, AC susceptibility measurements in the frequency range from 1 to $1500 \mathrm{~Hz}$ were performed in zero and non-zero static magnetic fields (Fig. 5). Evidently, there is a frequency-dependent nonzero out-of-phase signal for AC susceptibility below $3.5 \mathrm{~K}$ for both measurements. However, there is only one maximum for $B_{\mathrm{dc}}=0 \mathrm{~T}$, and therefore we cannot estimate $U_{\text {eff }}$ by fitting AC susceptibility data to the one-component Debye model and Arrhenius plot. Therefore, the data for $B_{\mathrm{dc}}=0 \mathrm{~T}$ were analyzed using the approximate relationship ${ }^{24}$

$$
\ln \left(\chi^{\prime \prime} / \chi^{\prime}\right)=\ln \left(2 \pi f \tau_{0}\right)+U_{\text {eff }} / k T
$$

giving the following values of the energy barrier $\left(U_{\text {eff }} / \mathrm{cm}^{-1}\right)$ and relaxation time $\left(\tau / 10^{-6} \mathrm{~s}\right): 8.9,0.35$ for $f=15.5 \mathrm{~Hz}, 8.4,1.2$ for $f=38.6 \mathrm{~Hz}, 9.3,1.1$ for $f=96.2 \mathrm{~Hz}, 9.8,1.3$ for $f=240 \mathrm{~Hz}, 12,0.51$ for $f=597 \mathrm{~Hz}, 12,1.4$ for $f=1490 \mathrm{~Hz}$ (Fig. 6). The slight variation

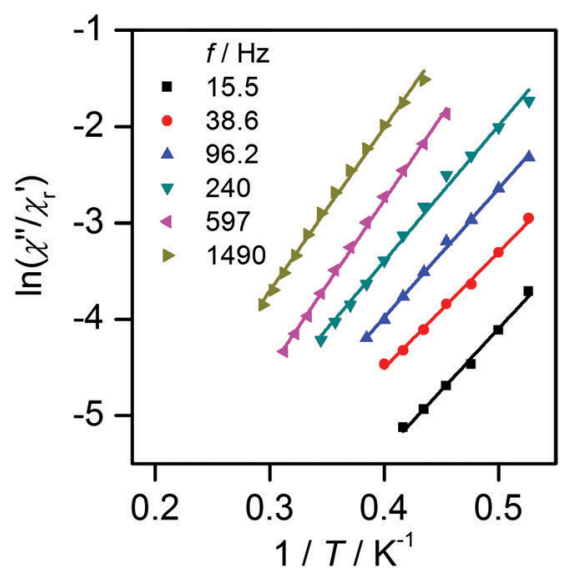

Fig. 6 Analysis of the AC susceptibility data measured in a zero static external field according to eqn (4). 
of the fitted parameters $\left(U_{\text {eff }}=8.4-12 \mathrm{~cm}^{-1}\right)$ is most likely caused by omitting the distribution of the relaxation processes.

\section{Conclusions}

In this work, we reported on the synthesis, structural and magnetic properties of two isostructural compounds $\left[\mathrm{M}_{4}^{\mathrm{II}}(\mathrm{L})_{4}\left(\mathrm{CH}_{3} \mathrm{OH}\right)_{2}\right]$ ( $\mathrm{M}=\mathrm{Ni}(\mathbf{1})$, Co (2)). The crystal structure of $\mathbf{1}$ revealed that this compound possesses a $\left\{\mathrm{Ni}_{4} \mathrm{O}_{6}\right\}^{2-}$ core with a defective dicubane topology and with mixed penta- and hexa-coordination. The isostructurality of 2 was confirmed by powder X-ray diffraction measurements. The analysis of variable temperature magnetic data by applying the spin Hamiltonian formalism revealed competing ferro- and antiferromagnetic interactions leading to the $S=0$ ground state in $\mathbf{1}$, but in $\mathbf{2}$ the exchange interactions are of ferromagnetic nature providing thus the $S=6$ ground state. The analysis of experimental data was supported by theoretical calculations and the use of BS-DFT calculations resulted in prediction of the magnetic exchange coupling constants, which agree rather well with those obtained from the experiment in the case of compound 1. In 2, the calculated exchange couplings were also predicted to be of prevailing antiferromagnetic nature and this is in stark contrast to the results of the fitting of the experimental data. With the aim to elucidate this contradiction and to obtain magnetic anisotropy parameters for each metal atom in $\mathbf{1}$ and 2, multiconfigurational CASSCF/NEVPT2 calculations were performed. As a result, large magnetic anisotropy both for penta- and hexacoordinate $\mathrm{Ni}$ (II)/Co(II) atoms was predicted. More importantly, it was revealed that the first excited states in $\mathbf{2}$ are very close to the ground state and thus the spin Hamiltonian formalism is not valid anymore. In other words, the magnetism of $\mathrm{Co}$ (II) atoms in 2 cannot be adequately described by a well-separated spin state with $S=3 / 2$. Therefore, in 2 , all the fitted or computed magnetic parameters derived within the spin Hamiltonian formalism must be taken with great care. Thus, the above-mentioned discrepancy between the DFT-calculated J-parameters of 2 and the experimental magnetic data stem from the fact that singledeterminant calculations, such as those based on DFT, cannot properly account for the multiconfigurational character of the $\mathrm{Co}$ (II) atoms in $\mathbf{2}$ and the large contribution of the angular momentum to the ground state. Furthermore, the large magnetic anisotropy in $\mathbf{2}$ resulted also in the observation of the slow relaxation of the magnetization in the zero-applied static magnetic field, which makes 2 only the first example of a single-molecule magnet with the $\left\{\mathrm{Co}_{4} \mathrm{O}_{6}\right\}^{2+}$ defective dicubane core and mixed hexa- and pentacoordination of the central atoms.

\section{Experimental}

\section{Synthesis}

All used chemicals and solvents were purchased from commercial sources and used without any further purification.

$\left[\mathrm{Ni}_{4}(\mathbf{L})_{4}\left(\mathrm{CH}_{3} \mathrm{OH}\right)_{2}\right]$ (1). An orange solution of $\mathrm{H}_{2} \mathrm{~L}(0.05 \mathrm{~g}$, $0.23 \mathrm{mmol})$ in $\mathrm{CH}_{3} \mathrm{OH}\left(30 \mathrm{~cm}^{3}\right)$ was mixed with a green solution of $\mathrm{Ni}\left(\mathrm{CH}_{3} \mathrm{COO}\right)_{2} \cdot 4 \mathrm{H}_{2} \mathrm{O}(0.06 \mathrm{~g}, 0.23 \mathrm{mmol})$ in $\mathrm{CH}_{3} \mathrm{OH}\left(10 \mathrm{~cm}^{3}\right)$ and the resultant red solution was stirred for $15 \mathrm{~min}$. Tripropylamine $\left(0.07 \mathrm{~g}, 0.48 \mathrm{mmol}\right.$ in $3 \mathrm{ml}$ of $\left.\mathrm{CH}_{3} \mathrm{OH}\right)$ was then added dropwise. The reaction mixture was refluxed for next 15 minutes and the brownish orange precipitate was filtered off. The mother liquor was left undisturbed at room temperature, and dark green prism shaped crystals were obtained after a few days. Yield: 61\%. Elemental analysis (crystalline phase): Anal. calcd for $\mathrm{C}_{54} \mathrm{H}_{44} \mathrm{~N}_{4} \mathrm{O}_{10} \mathrm{Ni}_{4}$ (1143.74): C, 56.7; H, 3.9; N, 4.9. Found: C, 56.8; H, 3.9; N, 4.8. FT-IR (ATR; $\left.\mathrm{cm}^{-1}\right)$ : 3055(m), 3002(m), 2909(m), 2835(m), 2774(m), 1617(s), 1587(s), 1538(m), 1439(s), 1380(m), 1336(w), 1296(s), 1253(s), 1220(m), 1169(w), 1153(m), 1124(w), 1109(w), 1024(m), 919(w), 828(m), 737(s), 618(w), 517(w), 492(w), 450(w).

$\left[\mathrm{Co}_{4}(\mathbf{L})_{4}\left(\mathrm{CH}_{3} \mathrm{OH}\right)_{2}\right]$ (2). The synthesis was performed under an inert $\mathrm{N}_{2}$ atmosphere. An orange solution of $\mathrm{H}_{2} \mathrm{~L}(0.05 \mathrm{~g}$, $0.23 \mathrm{mmol})$ in $\mathrm{CH}_{3} \mathrm{OH}\left(30 \mathrm{~cm}^{3}\right)$ was mixed with a red solution of $\mathrm{Co}\left(\mathrm{CH}_{3} \mathrm{COO}\right)_{2} \cdot 4 \mathrm{H}_{2} \mathrm{O}(0.06 \mathrm{~g}, 0.23 \mathrm{mmol})$ in $\mathrm{CH}_{3} \mathrm{OH}\left(10 \mathrm{~cm}^{3}\right)$ and the resultant brown orange solution was stirred for $15 \mathrm{~min}$. Tripropylamine $\left(0.07 \mathrm{~g}, 0.48 \mathrm{mmol}\right.$ in $3 \mathrm{ml}$ of $\left.\mathrm{CH}_{3} \mathrm{OH}\right)$ was then added dropwise. The reaction mixture was stirred for next 15 minutes and a brownish orange precipitate was filtered off. The mother liquor was left undisturbed at room temperature and a red microcrystalline powder was obtained after a few days. Yield: 69\%. Anal. calcd for $\mathrm{C}_{53} \mathrm{H}_{40} \mathrm{~N}_{4} \mathrm{O}_{9} \mathrm{Co}_{4}$ (1112.66): C, 57.2; H, 3.6; N, 5.0. Found: C, 57.3; H, 3.3; N, 4.9. FT-IR (ATR; $\left.\mathrm{cm}^{-1}\right)$ : 3060(m), 3015(m), 2917(m), 1600(s), 1581(s), 1542(m), 1434(s), 1378(m), 1328(w), 1278(s), 1235(s), 1214(m), 1168(w), 1144(m), 1125(w), 1106(w), 1035(m), 920(w), 826(m), 739(s), 606(w), 511(w), 489(w), 446(w).

\section{Equipment, measurements and software}

Elemental analysis was performed on a Thermo Scientific FLASH 2000 CHNS-O Analyzer. Infrared spectra of the compounds were recorded with a ThermoNicolet Nexus 670 FT-IR spectrometer using the ATR technique on a diamond plate in the region of 4000-400 $\mathrm{cm}^{-1}$. Temperature dependent $(T=1.9-300 \mathrm{~K}, B=0.1 \mathrm{~T})$ and field dependent $(B=0-7 \mathrm{~T}$, $T=2$ and $5 \mathrm{~K}$ ) magnetic measurements were carried out on powder samples on a SQUID magnetometer MPMS-XL7 (Quantum Design) for 1 and a PPMS Dynacool system (Quantum Design) with the VSM option for 2 . The data were corrected for the diamagnetism of the constituents.

X-ray diffraction analysis. Single crystal X-ray diffraction data are listed in Table S1 (ESI $\dagger$ ). The data were acquired using an Oxford diffraction Xcalibur 2 CCD diffractometer with a Sapphire CCD detector, a sealed tube (Mo $\mathrm{K} \alpha$ radiation, $\mathrm{K} \alpha=$ $0.71073 \AA$ ) and equipped with an Oxford Cryosystems nitrogen gas-flow apparatus. The CrysAlis program package (version 1.171.33.52, Oxford Diffraction) was used for data collection and reduction. ${ }^{25}$ The molecular structures were solved by direct methods SHELX-2014 and all non-hydrogen atoms were refined anisotropically on $F^{2}$ using the full-matrix least-squares procedure SHELXL-2014. ${ }^{26}$ All the hydrogen atoms were found in differential Fourier maps and their parameters were refined using a riding model with $U_{\text {iso }}(\mathrm{H})=1.2\left(\mathrm{CH}, \mathrm{CH}_{2}, \mathrm{OH}\right)$ or $1.5 U_{\text {eq }}\left(\mathrm{CH}_{3}\right)$. The X-ray 
powder diffraction patterns of all solid samples were recorded on a Mini-Flex600 (Rigaku) instrument equipped with BraggBrentano geometry, and with iron-filtered $\mathrm{Cu} \mathrm{K} \alpha 1,2$ radiation.

Theoretical methods. Ab initio theoretical calculations were performed with an ORCA 3.0.3 computational package. ${ }^{16}$ Single point DFT energy calculations based on X-ray geometries were done using the B3LYP functional. ${ }^{27}$ The isotropic exchange constants $J$ were calculated by comparing the energies of high-spin (HS) and broken-symmetry spin (BS) states using Ruiz's approach. ${ }^{28}$ Calculations of the ZFS parameters were performed using the state average complete active space selfconsistent field (SA-CASSCF) ${ }^{29}$ wave functions complemented by $\mathrm{N}$-electron valence second order perturbation theory (NEVPT2). ${ }^{30}$ The active spaces of the CASSCF calculations comprise five metal-based d-orbitals and eight electrons for nickel atoms, and seven electrons for cobalt atoms, $\operatorname{CAS}(8,5)$ and $\operatorname{CAS}(7,5)$, respectively. In the state averaged approach all multiplets for the given electron configuration were equally weighted, which means 10 triplet and 15 singles states for nickel atoms, and 10 quartet and 40 doublet states for cobalt atoms. The ZFS parameters, based on dominant spin-orbit coupling contributions from excited states, were calculated through the quasi-degenerate perturbation theory (QDPT), ${ }^{31}$ in which approximations to the Breit-Pauli form of the spinorbit coupling operator (SOMF approximation) ${ }^{32}$ and the effective Hamiltonian theory ${ }^{33}$ were utilized. In DFT calculations, the relativistic version of the polarized triple- $\xi$ quality basis set (def2-TZVP(-f)) proposed by Ahlrichs and coworkers was used for all atoms, whereas in the case of CASSCF calculations the relativistic version of def2-TZVP(-f) was used for $\mathrm{Co} / \mathrm{Ni}, \mathrm{N}, \mathrm{O}$ atoms and def2-SVP was used for $\mathrm{C}$ and $\mathrm{H}$ atoms. ${ }^{34}$ We also used the RI approximation with the decontracted auxiliary def2-TZV/J or def2-TZV/C Coulomb fitting basis sets and the chain-of-spheres approximation to exact exchange. ${ }^{35}$ Increased integration grids (Grid5 in ORCA convention) and tight SCF convergence criteria were used in all calculations. Analogous calculations were also done for the optimized geometries of $\mathbf{1}$ and 2, where the respective geometries were optimized using the BP86 functional and ZORA with the relativistic version def2-TZVP(-f) for Ni/Co, N, O atoms and def2-SVP for $\mathrm{C}$ and $\mathrm{H}$ atoms. Atom pairwise dispersion correction to the DFT energy with Becke-Johnson damping (D3BJ) was also included. ${ }^{36}$ The list of optimized atomic coordinates is available in the ESI $\dagger$ in Tables S4 and S5.

\section{Conflicts of interest}

There are no conflicts to declare.

\section{Acknowledgements}

We acknowledge financial support from the National Programme of Sustainability I (LO1305) of the Ministry of Education, Youth and Sports of the Czech Republic, and from Palacký University in Olomouc (PrF_2016_007 and PrF_2017_018).

\section{Notes and references}

1 R. Sessoli, D. Gatteschi, A. Caneschi and M. A. Novak, Nature, 1993, 365, 141-143.

2 (a) C. J. Milios, A. Vinslava, W. Wernsdorfer, E. K. Moggach, S. Parsons, S. P. Perlepes, G. Christou and E. K. Brechin, J. Am. Chem. Soc., 2007, 129, 2754-2755; (b) Y.-N. Guo, G.-F. Xu, W. Wernsdorfer, L. Ungur, Y. Guo, J. Tang, H.-J. Zhang, L. F. Chibotaru and A. K. Powell, J. Am. Chem. Soc., 2011, 133, 11948-11951; (c) R. J. Blagg, L. Ungur, F. Tuna, J. Speak, P. Comar, D. Collison, W. Wernsdorfer, E. J. L. McInnes, L. F. Chibotaru and R. E. P. Winpenny, Nat. Chem., 2013, 5, 673-678; (d) J. M. Zadrozny, M. Atanasov, A. M. Bryan, C.-Y. Lin, B. D. Rekken, P. P. Power, F. Neese and J. R. Long, Chem. Sci., 2013, 4, 125-138; (e) Y.-Y. Zhu, C. Cui, Y.-Q. Zhang, J.-H. Jia, X. Guo, C. Gao, K. Qian, S.-D. Jiang, B.-W. Wang, Z.-M. Wang and S. Gao, Chem. Sci., 2013, 4, 1802-1806.

3 (a) S. K. Singh, M. F. Beg and G. Rajaraman, Chem. - Eur. J., 2016, 22, 672-680; (b) C. Das, A. Upadhyay, S. Vaidya, S. K. Singh, G. Rajaraman and M. Shanmugam, Chem. Commun., 2015, 51, 6137-6140; (c) S. K. Singh, T. Gupta and G. Rajaraman, Inorg. Chem., 2014, 53, 10835-10845; (d) K. Katoh, R. Asano, A. Miura, Y. Horii, T. Morita, B. K. Breedlove and M. Yamashita, Dalton Trans., 2014, 43, 7716-7725; (e) M. Atanasov, F. Neese, F. Grandjean and G. J. Long, Inorg. Chem., 2013, 52, 13123-13131; $(f)$ K. Katoh, H. Isshiki, T. Komeda and M. Yamashita, Coord. Chem. Rev., 2011, 255, 2124-2148.

4 (a) I. A. Kuhne, N. Magnani, V. Mereacre, W. Wernsdorfer, C. Anson and A. K. Powell, Chem. Commun., 2014, 50, 1882-1885; (b) J.-L. Liu, W.-Q. Lin, Y.-C. Chen, J.-D. Leng, F.-S. Guo and M.-L. Tong, Inorg. Chem., 2013, 52, 457-463; (c) G. P. Guedes, S. Soriano, N. M. Comerlato, N. L. Speziali, M. A. Novak and M. G. F. Vaz, Inorg. Chem. Commun., 2013, 37, 101-105; (d) M. Ibrahim, Y. Lan, B. S. Bassil, Y. Xiang, A. Suchopar, A. K. Powell and U. Kortz, Angew. Chem., Int. Ed., 2011, 50, 4708-4711.

5 (a) S. Gómez-Coca, D. Aravena, R. Morales and E. Ruiz, Coord. Chem. Rev., 2015, 289-290, 379-392; (b) S. GómezCoca, E. Cremades, N. Aliaga-Alcalde and E. Ruiz, Inorg. Chem., 2014, 53, 676-678; (c) R. Herchel, L. Váhovská, I. Potočňák and Z. Trávníček, Inorg. Chem., 2014, 53, 5896-5898.

6 (a) M. Pait, A. Bauzá, A. Frontera, E. Colacio and D. Ray, Inorg. Chem., 2015, 54, 4709-4723; (b) Y.-Z. Gao, Y.-A. Zhang and J. Zhang, Inorg. Chem. Commun., 2015, 54, 85-88; (c) P. S. Perlepes, A. A. Athanasopoulou, K. I: Alexopoulou, C. P. Raptopoulou, V. Psycharis, A. Escuer, S. P. Perlepes and T. C. Stamatatos, Dalton Trans., 2014, 43, 16605-16609; (d) S.-H. Zhang, Y. D. Zhang, H. H. Zou, J. J. Guo, H. P. Li, Y. Song and H. Liang, Inorg. Chim. Acta, 2013, 396, 119-125; (e) S. Petit, P. Neugebauer, G. Pilet, G. Chastanet, A.-L. Barra, A. B. Antunes and W. Wernsdorfer, D: Luneau, Inorg. Chem., 2012, 51, 6645-6654; $(f)$ S.-H. Zhang, L.-F. Ma, H.-H. Zou, Y. G. Wang, H. Liang and M. H. Zeng, Dalton Trans., 2011, 
40, 11402-11409; ( $g$ ) A. Scheurer, A. M. Ako, R. W. Saalfrank, F. W. Heinemann, F. Hampel, K. Petukhov, K. Gieb, M. Stocker and P. Muller, Chem. - Eur. J., 2010, 16, 4784-4792; (h) L. Zhao, J. Wu, H. Ke and J. Tang, Inorg. Chem., 2014, 53, 3519-3525; ( $i$ ) H. Ke, L. Zhao, Y. Guo and J. Tang, Inorg. Chem., 2012, 51, 2699-2705.

7 (a) F. J. Klinke, A. Das, S. Demeshko, S. Dechert and F. Meyer, Inorg. Chem., 2014, 53, 2976-2982; (b) A. Ghisolfi, K. Y. Monakhov, R. Pattacini, P. Braunstein, X. López, C. de Graaf, M. Speidrich, J. van Leusen, H. Schilder and P. Kogerler, Dalton Trans., 2014, 43, 7847-7859; (c) S. Hameury, L. Kayser, R. Pattacini, G. Rogez, W. Wernsdorefer and P. Braunstein, Dalton Trans., 2013, 42, 5013-5024; (d) G. Aromí, E. Bouwman, E. Burzurí, C. Carbonera, J. Krzystek, F. Luis, C. Schlegel, J. van Slageren, S. Tanase and S. J. Teat, Chem. - Eur. J., 2008, 14, 11158-11166; (e) P. L. Feng, C. C. Beedle, C. Koo, J. Lawrence, S. Hill and D. N. Hendrickson, Inorg. Chim. Acta, 2008, 361, 3465-3480; $(f)$ A. Ferguson, J. Lawrence, A. Parkin, J. SanchezBenitez, K. V. Kamenev, E. K. Brechin, W. Wernsdorfer, S. Hill and M. Murrie, Dalton Trans., 2008, 6409-6414; (g) E.-C. Yang, W. Wernsdorfer, L. N. Zakharov, Y. Karaki, A. Yamaguchi, R. M. Isidro, G.-D. Lu, S. A. Wilson, A. L. Rheingold, H. Ishimoto and D. N. Hendrickson, Inorg. Chem., 2006, 45, 529-546; (h) M. Moragues-Cánovas, M. Helliwell, L. Ricard, E. Riviere, W. Wernsdorfer, E. Brechin and T. Mallah, Eur. J. Inorg. Chem., 2004, 2219-2222.

8 (a) P. Khakhlary, C. E. Anson, A. Mondal, A. K. Powell and J. B. Baruah, Dalton Trans., 2015, 44, 2964-2969; (b) S. Liu, S. Wang, F. Cao, H. Fu, D. Li and J. Dou, RSC Adv., 2012, 2, 1310-1313; (c) S. Banerjee, M. Nandy, S. Sen, S. Mandal, G. M. Rosair, A. M. Z. Slawin, C. J. Gómez-García, J. M. Clemente-Juan, E. Zangrando, N. Guidolin and S. Mitra, Dalton Trans., 2011, 40, 1652-1661; (d) R. Pattacini, P. Teo, J. Zhang, Y. Lan, A. K. Powell, J. Nehrkorn, O. Waldmann, T. S. Andy Hor and P. Braumstein, Dalton Trans., 2011, 40, 10526-10534; (e) S. G. Telfer, R. Kuroda, J. Lefebvre and D. B. Leznoff, Inorg. Chem., 2006, 45, 4592-4601; $(f)$ M. Koikawa, M. Ohba and T. Tokii, Polyhedron, 2005, 24, 2257-2262.

9 (a) I. Oyarzabal, J. Ruiz, A. J. Mota, A. Rodriguez-Diégez, J. M. Seco and E. Colacio, Dalton Trans., 2015, 44, 6825-6838; (b) D. Das, G. Mahata, A. Adhikary, S. Konar and K. Biradha, Cryst. Growth Des., 2015, 15, 4132-4141; (c) L. Botana, J. Ruiz, A. J. Mota, A. Rodriguez-Diéguez, J. M. Seco, I. Oyarzabal and E. Colacio, Dalton Trans., 2014, 43, 13509-13524; (d) T. Nakajima, K. Seto, A. Scheurer, B. Kure, T. Kajiwara, T. Tanase, M. Mikuriya and H. Sakiyama, Eur. J. Inorg. Chem., 2014, 5021-5033; (e) R. Modak, Y. Sikdar, S. Mandal, C. J. Gómez-García, S. Benmansour, S. Chatterjee and S. Goswami, Polyhedron, 2014, 70, 155-163; $(f)$ H.-H. Chen, J. Yang, Y.-Y. Liu and J.-F. Ma, CrystEngComm, 2013, 15, 5168-5178; ( $g$ ) H.-S. Wang and Y. Song, Inorg. Chem. Commun., 2013, 35, 86-88; (h) J.-P. Zhao, R. Zhao, Q. Yang, B.-W. Hu, F.-C. Liu and X.-H. Bu, Dalton Trans., 2013, 42, 14509-14515; (i) P.-P. Yang, C.-Y. Shao, Y. Xu and L.-L. Zhu, Z. Anorg. Allg. Chem., 2013, 639,
548-551; (j) S.-Y. Lin, G.-F. Xu, L. Zhao, Y.-N. Guo, J. Tang, Q.-L. Wang and G.-X. Liu, Inorg. Chim. Acta, 2011, 373, 173-178; (k) A. N. Georgopoulou, C. P. Raptopoulou, V. Psycharis, R. Ballesteros, B. Abarca and A. K. Boudalis, Inorg. Chem., 2009, 48, 3167-3176; (l) A. K. Boudalis, C. P. Raptopoulou, V. Psycharis, B. Abarca and R. Ballesteros, Eur. J. Inorg. Chem., 2008, 3796-3801; (m) C. G. Efthymiou, C. P. Raptopoulou, A. Terzis, R. Boča, M. Korabic, J. Mrozinski, S. P. Perlepes and E. G. Bakalbassis, Eur. J. Inorg. Chem., 2006, 2236-2252; (n) P. King, R. Clérac, W. Wernsdorfer, C. E. Anson and A. K. Powell, Dalton Trans., 2004, 2670-2676.

10 (a) M. Cindrić, G. Pavlović, D. Pajić, K. Zadro, D. Cinčić, T. Hrenar, E. Lekšić, A. Belen Pinar Prieto, P. Lazić and D. Šišak Jung, New J. Chem., 2016, 40, 6604-6614; (b) J. Wang, C. Feng, C. M. Ge, S. Zhang and H. Hai, J. Cluster Sci., 2016, 27, 2001-2011; (c) R. Modak, Y. Sikdar, A. E. Thuijs, G. Christou and S. Goswami, Inorg. Chem., 2016, 55, 10192-10202; (d) E. Loukopoulos, B. Berkoff, K. Griffiths, V. Keebié, V. N. Dokorou, A. C. Tsipis, A. Escuer and G. E. Kostakis, CrystEngComm, 2015, 17, 6753-6764.

11 R. Herchel, I. Nemec, M. Machata and Z. Trávníček, Dalton Trans., 2016, 45, 18622-18634.

12 A. W. Addison, T. N. Rao, J. Reedijk, J. Vanrijn and G. C. Verschoor, J. Chem. Soc., Dalton Trans., 1984, 1349-1356.

13 R. Herchel, I. Nemec, M. Machata and Z. Trávníček, Inorg. Chem., 2015, 54, 8625-8638.

14 J.-D. Leng, S.-K. Xing, R. Herchel, J.-L. Liu and M.-L. Tong, Inorg. Chem., 2014, 53, 5458-5466.

15 M. Machata, I. Nemec, R. Herchel and Z. Trávníček, RSC Adv., 2017, 7, 25821-25827.

16 F. Neese, WIREs Comput. Mol. Sci., 2012, 2, 73-78.

17 F. Neese, Coord. Chem. Rev., 2009, 253, 526-563.

18 I. Nemec, R. Herchel, I. Svoboda, R. Boča and Z. Trávníček, Dalton Trans., 2015, 44, 9551-9560.

19 J. Titiš and R. Boča, Inorg. Chem., 2010, 49, 3971-3973.

20 I. Nemec, R. Herchel, X. Zhang and Z. Trávniček, Synth. Met., 2016, 215, 158-163.

21 J. Titiš and R. Boča, Inorg. Chem., 2011, 50, 11838-11845.

22 R. Herchel, Z. Dvořák, Z. Trávníček, M. Mikuriya, R. R. Louka, F. A. Mautner and S. S. Massoud, Inorg. Chim. Acta, 2016, 451, 102-110.

23 R. Boča, A Handbook of Magnetochemical Formulae, Elsevier, 2012.

24 (a) J. Bartolomé, G. FIloti, V. Kuncser, G. Schinteie, V. Mereacre, C. E. Anson, A. K. Powell, D. Prodius and C. Turta, Phys. Rev. B: Condens. Matter Mater. Phys., 2009, 80, 014430; (b) R. Ishikawa, R. Miyamoto, H. Nojiri, B. K. Breedlove and M. Yamashita, Inorg. Chem., 2013, 52, 8300-8302.

25 CrysAlis software package, Version 1.171.33.52, Agilent Technologies, Yarnton, England.

26 G. M. Sheldrick, Acta Crystallogr., Sect. C: Struct. Chem., 2015, 71, 3-8.

27 (a) C. Lee, W. Yang and R. G. Parr, Phys. Rev. B: Condens. Matter Mater. Phys., 1988, 37, 785-789; (b) A. D. Becke, 
J. Chem. Phys., 1993, 98, 1372-1377; (c) A. D. Becke, J. Chem. Phys., 1993, 98, 5648-5652; (d) P. L. Stephens, F. J. Devlin, C. F. Chabalowski and M. J. Frisch, J. Phys. Chem., 1994, 98, 11623-11627.

28 (a) E. Ruiz, A. Rodríguez-Fortea, J. Cano, S. Alvarez and P. Alemany, J. Comput. Chem., 2003, 24, 982-989; (b) E. Ruiz, J. Cano, S. Alvarez and P. Alemany, J. Comput. Chem., 1999, 20, 1391-1400.

29 P. A. Malmqvist and B. O. Roos, Chem. Phys. Lett., 1989, 155, 189-194.

30 (a) C. Angeli, R. Cimiraglia, S. Evangelisti, T. Leininger and J. P. Malrieu, J. Chem. Phys., 2001, 144, 10252-10256; (b) C. Angeli, R. Cimiraglia and J. P. Malrieu, Chem. Phys. Lett., 2001, 350, 297-305; (c) C. Angeli, R. Cimiraglia and J. P. Malrieu, J. Chem. Phys., 2002, 117, 9138-9153; (d) S. Borini, M. Cestari and R. Cimiraglia, J. Chem. Phys.,
2004, 121, 4043-4049; (e) C. Angeli, B. Bories, A. Cavallini and R. Cimiraglia, J. Chem. Phys., 2006, 124, 054108.

31 D. Ganyushin and F. Neese, J. Chem. Phys., 2006, 125, 024103. 32 F. Neese, J. Chem. Phys., 2005, 122, 034107.

33 R. Maurice, R. Bastardis, C. Graaf, N. Suaud, T. Mallah and N. Guihéry, J. Chem. Theory Comput., 2009, 5, 2977-2984. 34 (a) A. Schafer, H. Horn and R. Ahlrichs, J. Chem. Phys., 1992, 97, 2571-2577; (b) A. Schafer, C. Huber and R. Ahlrichs, J. Chem. Phys., 1994, 100, 5829-5835; (c) F. Weigend and R. Ahlrichs, Phys. Chem. Chem. Phys., 2005, 7, 3297-3305.

35 (a) F. Neese, F. Wennmohs, A. Hansen and U. Becker, Chem. Phys., 2009, 356, 98-109; (b) R. Izsak and F. Neese, J. Chem. Phys., 2011, 135, 144105.

36 (a) S. Grimme, J. Antony, S. Ehrlich and H. Krieg, J. Chem. Phys., 2010, 132, 154104; (b) S. Grimme, S. Ehrlich and L. Goerigk, J. Comput. Chem., 2011, 32, 1456-1465. 